\title{
Liquidity: \\ Considerations of a Portfolio Manager
}

\author{
Laurie Simon Hodrick and Pamela C. Moulton*
}

\begin{abstract}
This paper examines liquidity and how it affects the behavior of portfolio managers, who account for a significant portion of trading in many assets. We define an asset to be perfectly liquid if a portfolio manager can trade the quantity she desires when she desires at a price not worse than the uninformed expected value. A portfolio manager is limited by both what she needs to attain and the ease with which she can attain it, making her sensitive to three dimensions of liquidity: price, timing, and quantity. Deviations from perfect liquidity in any of these dimensions impose shadow costs on the portfolio manager. By focusing on the trade-off between sacrificing on price and quantity instead of the canonical price-time trade-off, the model yields several novel empirical implications. Understanding a portfolio manager's liquidity considerations provides important insights into the liquidity of many assets and asset classes.
\end{abstract}

This paper examines liquidity and how it affects investor behavior, focusing on the considerations of a mutual fund portfolio manager. US mutual funds are the largest investor in US commercial paper with $47 \%$, and they hold $35 \%$ of US tax-exempt debt, $27 \%$ of US equities, and about $10 \%$ of US corporate, Treasury, and agency debt (Investment Company Institute, 2008). Total mutual fund holdings worldwide equaled \$26 trillion at year-end 2007. An understanding of the liquidity considerations of a portfolio manager therefore provides important insights into the liquidity of many assets and asset classes.

A portfolio manager seeks to optimize the performance of her portfolio relative to her performance benchmarks. In this pursuit, she is limited by both what she needs to attain and the ease with which she can attain it. This makes her sensitive to three dimensions of liquidity: price, timing, and quantity. Deviations from perfect liquidity in any of these dimensions impose shadow costs on the portfolio manager, making them key considerations in her portfolio decisions.

We define an asset to be perfectly liquid if a portfolio manager can trade the quantity she desires when she desires at a price not worse than the uninformed expected value. A few examples serve to motivate the three dimensions of liquidity and their shadow costs. Quantity may be the most important consideration for passive portfolio managers, such as those who are bound by prospectus

The authors thank Bill Christie (the Editor), Larry Glosten, Joel Hasbrouck, Charles Jones, Pete Kyle, Subra Subrahmanyam, Suresh Sundaresan, Mick Swartz, Vish Viswanathan, two anonymous referees, and seminar participants at CUNY, Columbia University, Duke University, the Five Star Conference, the London School of Economics Liquidity Conference, Purdue University, Rutgers University, University of Connecticut, University of North Carolina, and the Wharton School for helpful comments. Part of this research was conducted while Hodrick was a director/trustee of Merrill Lynch Investment Managers (MLIM) and Moulton was a senior economist at the New York Stock Exchange. The opinions expressed in this paper are the authors' alone and not those of MLIM, the Merrill Lynch Funds, any of their employees, officers, or directors, nor do they necessarily reflect the opinions of the members, officers, or employees of the New York Stock Exchange.

${ }^{*}$ Laurie Simon Hodrick is a Professor of Finance and Economics and the A. Barton Hepburn Professor of Economics the A. Barton Hepburn Professor of Economics in the Faculty of Business at Columbia Business School, New York, NY. Pamela C. Moulton is an Assistant Professor of Finance and Economics at Fordham Graduate School of Business in New York, NY. 
to closely replicate an index. ${ }^{1}$ As of year-end 2007 , indexed assets equaled approximately $30 \%$ of the $\$ 4.85$ trillion benchmarked to the Standard and Poor's (S\&P) 500 Index (Journal of Indexes, 2005). Timing may be the most important consideration for portfolio managers liquidating asset holdings in response to significant mutual fund redemptions. Annual redemption rates have exceeded $25 \%$ each year over the past two decades and have been in excess of 50\% (Investment Company Institute, 2008). ${ }^{2}$ Price may be the most important consideration for active portfolio managers in pursuit of value.

Ours is a theoretical model with three risk-neutral agents, a liquidity provider, an informed trader, and an uninformed investor (the portfolio manager), all of whom are rational. The main innovation of our model is that we allow the uninformed investor to choose whether and how much to trade. In early papers on liquidity, Bagehot (1971) and Black (1971) describe liquidity as the trade-off between sacrificing on price and timing, assuming that a trader always trades her desired quantity. This assumption has been largely maintained in the subsequent theoretical literature, begun by Copeland and Galai (1983) and continued by Glosten and Milgrom (1985) and Easley and O'Hara (1987), with O'Hara (1995), for example, defining a liquid market as one that accommodates trading with the least effect on price. ${ }^{3}$ Here we focus on the trade-off between sacrificing on price and quantity instead of the canonical price-time trade-off. ${ }^{4}$

We characterize when assets are and are not traded, allowing us to predict the extent of trading in primary and secondary markets, portfolio managers' trading patterns after stock splits, and trade-size clustering in response to changes in fund disclosure requirements. We find that bid-ask spreads for some quantities may be decreasing in the prevalence of informed traders, providing a novel explanation for the narrowing of spreads in response to increased hedge fund presence. Finally, we find that private information specific to an asset may be more valuable when portfolio managers have an intense desire to trade that asset. This provides a new interpretation of the well-documented effects of inclusion in the S\&P 500 Index.

The organization of the paper is as follows. Section I develops the model. Section II explores the equilibria. Section III provides empirical predictions. Section IV concludes. Proofs of all propositions are in the Appendix.

\section{Model}

In this section we introduce the model. There is one period, and there are three risk-neutral agents. ${ }^{5}$ One is a liquidity provider who sets a price and quantity schedule for an asset. We allow this liquidity provider to be a specialist, a market maker, a dealer, or anyone who quotes a price for a particular quantity and stands ready to trade at that price. We deliberately abstract from

\footnotetext{
${ }^{1}$ The investment objectives and restrictions for a fund are established in the fund's "Statement of Additional Information." Goldstein and Kavajecz (2000) empirically document the link between fund manager aggressiveness and trading costs for actively versus passively managed funds.

${ }^{2} \mathrm{O}$ 'Neal (2004) provides evidence on mutual fund purchase and redemption rates. Bollen and Busse (2004) document that fund flow effects are large enough to distort inferences about mutual fund performance.

${ }^{3}$ This strand of the literature is distinct from that begun by Kyle (1985), who defines liquidity as the order flow needed to move price one unit, and followed by Admati and Pfleiderer (1988), Foster and Viswanathan (1990), and numerous subsequent researchers including Spiegel and Subrahmanyam (1992), who, in the theoretical model most similar in spirit to ours, endogenize the trading motives of uninformed agents within the Kyle framework.

${ }^{4}$ The key results of this model, which isolates the price-quantity trade-off, also emerge in a model including the pricetime-quantity trade-off; see Hodrick and Moulton (2005).
}

${ }^{5}$ A two-period extension can be found in Hodrick and Moulton (2005). 
many details of specific assets and market mechanisms to encompass the multitude of different assets that portfolio managers collectively trade.

There are also two types of liquidity demanders; for expositional clarity we name them the informed trader and the uninformed investor. The informed trader is motivated to trade by an information advantage. ${ }^{6}$ The uninformed investor is motivated to trade by an exogenous demand for quantity. We think of the mutual fund portfolio manager as an archetypal example of the uninformed investor for several reasons. Edelen (1999) documents that the requirement to guarantee redemption on demand forces portfolio managers to behave as uninformed investors relative to other classes of investors such as hedge funds. Warther (1995) and Vayanos (2004) confirm the influence of mutual fund redemptions on portfolio decisions. In addition, many mutual funds (including index funds) are constrained by their prospectus to pursue passive (noninformation-driven) strategies. Finally, Berk and Green (2004) show that passive investment strategies are often chosen by mutual funds with high past performance.

While there are two liquidity demanders, the informed trader and the uninformed investor, only one actually arrives to trade. With probability $\alpha, 0 \leq \alpha \leq 1$, it is the informed trader who arrives, and with probability $(1-\alpha)$, it is the uninformed investor who arrives. Whoever arrives chooses whether and what quantities to trade at the prices set by the liquidity provider, who is unable to determine which type of liquidity demander arrives.

We consider an asset market in which prices may be quoted for four quantities: a large and a small quantity on each side of the market. ${ }^{7}$ On the ask side, the liquidity provider is selling and the liquidity demander is buying; on the bid side, the liquidity provider is buying and the liquidity demander is selling. We denote a specific quantity as $Q^{i j}, i \in\{A, B\}, j \in\{S, L\}$; hence, the small and large quantities on the ask side are denoted $Q^{A S}$ and $Q^{A L}$, and the small and large quantities on the bid side are denoted $Q^{B S}$ and $Q^{B \mathrm{~L}}$. Consistent with the prior literature, $Q^{A L}>Q^{A S}>0>Q^{B S}>Q^{B L}$. The prices corresponding to these quantities are denoted $P^{A L}, P^{A S}$, $P^{B S}$, and $P^{B L}$.

The true value of the asset is denoted $P^{*}$, which is drawn from a binary distribution such that $P^{*}=P_{L}$ with probability $\delta$ and $P^{*}=P_{H}$ with probability $(1-\delta), 0 \leq \delta \leq 1 .^{8}$ Thus, the unconditional expected value of $P^{*}$ is $\delta P_{L}+(1-\delta) P_{H}$. The informed trader knows $P^{*}$ before trading begins. ${ }^{9}$ We denote by $\phi^{i j \mid x}$ the probability that the informed trader endogenously chooses to trade $Q^{i j}$ given that he arrives to trade and $P^{*}=x, x \in\left\{P_{L}, P_{H}\right\}$. The probability of the informed trader trading $Q^{i j}$, equal to the sum of the likelihood of each $P^{*}$ realization times the conditional probability that the informed trader trades given that realization, is $\delta \phi^{i j \mid P L}+(1-\delta) \phi^{i j \mid P H}$.

The portfolio manager, as the uninformed investor, is motivated to trade by an exogenous demand for quantity, $Q^{*}$. The uninformed investor receives $Q^{*}$ before the beginning of trading. $Q^{*}$ reflects sources of demand to trade a particular asset such as hedging, index replication, and portfolio rebalancing and may be prospectus driven. $Q^{*}$ may also be driven by past relative performance, as documented in Brown, Harlow, and Starks (1996). Note that $Q^{*}$ can equal zero in this model; in other words, the uninformed investor may have no exogenous desire to trade this

\footnotetext{
${ }^{6}$ Consistent with the prior literature, we preclude the informed trader from acting as a liquidity provider. For an analysis of such a case, see Bloomfield, O'Hara, and Saar (2005).

${ }^{7}$ The results that emerge when there are more quantities are qualitatively similar; we solve the model with two quantities on each side of the market for expositional simplicity.

${ }^{8}$ The binary distribution assumption allows comparability to the existing literature. The model is easily extendable to a general continuous distribution with density function $f\left(P^{*}\right)$.

${ }^{9}$ If instead there were multiple informed traders, they would all observe a common true value for the asset. We relax the assumption of one uninformed investor in Section II.C.
} 
asset. Further, as discussed below, even when $Q^{*}$ is nonzero the uninformed investor optimally chooses whether to trade her $Q^{*}$ or another quantity, including zero. ${ }^{10}$

A distribution of $Q^{*}$ is given by nature. We denote the probability that $Q^{*}=y$ by $\psi^{y}$, $y \in\left\{Q^{A L}, Q^{A S}, 0, Q^{B S}, Q^{B L}\right\} .{ }^{11}$ We denote by $\chi^{i j \mid y}$ the probability that the uninformed investor endogenously chooses to trade $Q^{i j}$ given that she arrives to trade and $Q^{*}=y$. Thus the probability of the uninformed investor trading $Q^{i j}$ is $\pi^{i j}=\sum_{y} \psi^{y} \chi^{i j l y}$.

\section{A. Agent Maximizations}

All three agents in our model are rational maximizers. The liquidity provider and the informed trader are deliberately reminiscent of their counterparts in the literature begun by Copeland and Galai (1983), Glosten and Milgrom (1985), and Easley and O'Hara (1987). This modeling choice isolates the effects of our main innovation: while under specific parameter values our model reduces directly to earlier models, in its general form we allow for greater richness in the uninformed investor's optimization.

\section{Liquidity Provider}

The liquidity provider is uninformed and cannot distinguish between the informed trader and the uninformed investor when a liquidity demander arrives to trade. We model the liquidity provider as a single agent, but we assume that (unmodeled) competition or the threat of competition drives his expected profits on each trade to zero. ${ }^{12}$

The liquidity provider solves the following maximization to determine ask prices

$$
\begin{aligned}
& \max _{P^{A S}, P^{A L}}(1-\alpha)\left[\pi^{A j} Q^{A j}\left(P^{A j}-E\right)\right] \\
& \quad-\alpha\left[(1-\delta)\left\{\phi^{A j \mid P H} Q^{A j}\left(P_{H}-P^{A j}\right)\right\}+\delta\left\{\phi^{A j \mid P L} Q^{A j}\left(P_{L}-P^{A j}\right)\right\}\right],
\end{aligned}
$$

s.t. zero expected profit for each quantity.

He solves the analogous maximization to determine bid prices.

The common knowledge uninformed expected value of $P^{*}$, denoted $E$, reflects all conditioning information available to uninformed agents, that is, to the uninformed investor and the liquidity provider. $E$ is therefore equal to the unconditional expected value of $P^{*}, \delta P_{L}+(1-\delta) P_{H}$.

The first line of the liquidity provider's maximization reflects his expected profit or loss from trading with the uninformed investor. The second line of the maximization reflects the liquidity provider's expected profit or loss from trading with the informed trader. The basic tension in the model arises from the two liquidity demanders' preferences and how they are reflected in the liquidity provider's price schedule.

\section{Informed Trader}

The informed trader, if he is the one to arrive, maximizes the gain from trading on his information

$$
\max _{Q^{i j}} Q^{i j}\left(P^{*}-P^{i j}\right)
$$

\footnotetext{
${ }^{10}$ Longstaff (2005) finds that asset illiquidity affects portfolio choice profoundly.

${ }^{11}$ The results presented here are robust to a more general distribution of $Q^{*}$; see Hodrick and Moulton (2005).

${ }^{12}$ For simplicity, we assume zero inventory and order-processing costs. The assumption of competitive liquidity providers is consistent with the previous literature such as Easley and O'Hara (1987).
} 
The informed trader buys if the asset's true value is above the ask price, sells if the true value is below the bid price, and does not trade if the true value is between the bid and ask prices. Equation (2) balances a nonnegative information advantage that measures what the informed trader would gain if prices did not reflect the possibility of his presence, $Q^{i j}\left(P^{*}-E\right)$, with a nonpositive information impact that measures how much of the information advantage he fails to capture if the possibility of his presence is reflected in the prices set by the liquidity provider, $Q^{i j}\left(E-P^{i j}\right)$.

\section{Uninformed Investor}

The portfolio manager, as an uninformed investor, seeks to optimize the performance of her portfolio relative to her performance benchmarks. In this pursuit she is limited by both what she needs to attain and the ease with which she can attain it. One important consideration for the uninformed investor is her inability to attain fair value, where this inability is defined as the quantity traded times the wedge between the uninformed expected value and the traded price. This quantifies any detrimental effect of trading in a market where prices are affected by the probabilistic presence of informed traders. The inability to attain fair value is nonpositive if ask prices are above and bid prices are below the uninformed expected value, in which case the portfolio manager's pain is minimized when quantities are smaller and prices are closer to the uninformed expected value. One would expect active portfolio managers to be particularly fair value sensitive, especially those in pursuit of value.

The second important consideration for the uninformed investor is satisfaction, defined as how strongly she cares about whether she attains her $Q^{*} .{ }^{13}$ Satisfaction captures the opportunity cost of not transacting a specific quantity but instead trading less than her exogenous demand. We conjecture that the desire for satisfaction is higher for passive portfolio managers, such as those who are bound by prospectus to closely replicate an index.

These considerations highlight that the uninformed investor is sensitive to both price and quantity. Her maximization can be expressed, in reduced form, as ${ }^{14}$

$$
\begin{array}{cll}
\max _{Q^{i j}} & Q^{i j}\left(E-P^{i j}\right)-\theta\left(Q^{*}-Q^{i j}\right) & \text { if } Q^{*} \geq 0, \\
& Q^{i j}\left(E-P^{i j}\right)-\theta\left(Q^{i j}-Q^{*}\right) & \text { if } Q^{*}<0 .
\end{array}
$$

The first term measures the uninformed investor's desire for fair value. In the second term, the uninformed investor's $\theta$ reflects the intensity of her desire for satisfaction, $0 \leq \theta \leq \infty$. Note that for the portfolio manager these terms encapsulate the tracking error resulting from trading at an inferior price and trading less than the target quantity.

The shadow costs of fair value and satisfaction and their interaction are key determinants of which quantity, if any, the uninformed investor chooses to trade in equilibrium. Note that if the uninformed investor does not trade the asset at all, her fair value effect is minimized, but she suffers from a lack of satisfaction. We expect that such a lack of satisfaction should be less

\footnotetext{
${ }^{13}$ Our desire for satisfaction encompasses the elasticity of demand in Glosten and Milgrom (1985). We conjecture that the desire for satisfaction is lower for assets with closer substitutes. For example, we expect a lower desire for satisfaction for Treasury bonds, whose substitutes include other Treasuries, futures, and options, than for municipal bonds, which have fewer close substitutes. In a general equilibrium model, the desire for satisfaction would motivate the uninformed investor to trade, but not necessarily to favor any particular asset within a set of substitutable assets.

${ }^{14}$ Our model is intended to reflect in reduced form a standard utility function with preferences driven by considerations such as the market timing, horizon effects, and hedging demand in Campbell, Grossman, and Wang (1993), Lo, Mamaysky, and Wang (2004), and Ait-Sahalia and Brandt (2001).
} 
consequential for a portfolio manager whose prospectus allows broad discretion than for one with less flexibility (as detailed in Bollen and Busse (2001)) and more consequential for a portfolio manager facing significant unexpected fund flows (Warther, 1995).

The inability to attain fair value, which is always nonpositive in equilibrium, can either complement or substitute for the desire for satisfaction. When a portfolio manager considers trading a quantity that is less than her $Q^{*}$, the desire for fair value pushes her to trade an even smaller quantity while the desire for satisfaction pushes her to trade more than her candidate quantity. In this case, the desire for fair value complements the desire for satisfaction. In contrast, when she considers trading a quantity in excess of her $Q^{*}$, the desires for fair value and satisfaction serve as substitutes and both push her to trade less than her candidate quantity. Finally, the desire for fair value is independent of the desire for satisfaction when her candidate quantity equals her exogenous demand. Proposition 1 summarizes the uninformed investor's preferences.

Proposition 1: The desire for fair value can complement, substitute for, or be independent of the desire for satisfaction. Hence, an uninformed investor need not always trade off satisfaction for fair value.

The proofs to this and all subsequent propositions are in the Appendix. ${ }^{15}$

Liquidity has traditionally been characterized as the trade-off between sacrificing on price and timing: an investor either accepts a worse price for fast execution of her quantity or waits for a better price to trade her quantity. The observation in Proposition 1 that the uninformed investor's desire for fair value can augment, offset, or be independent of her desire for satisfaction highlights the importance of examining the price-quantity trade-off. Since the uninformed investor's desires may be substitutes or complements, an uninformed investor need not always trade off satisfaction for fair value.

\section{Equilibria}

This section characterizes the equilibria that emerge from our theoretical model. While under specific assumptions on the uninformed investor's shadow costs this model maps directly to earlier models, the emergent equilibria can look quite different with the variation in the uninformed investor's optimization we allow. Intuitively, while in much of the preceding literature the uninformed investor trades exogenously, causing the informed trader's maximization to be the binding constraint in the model, here both agents behave optimally and therefore either maximization may prove to be the binding constraint. Empirical implications specific to mutual funds are detailed in Section III.

\section{A. Equilibrium Behavior}

We examine a rational expectations equilibrium in which prices and quantities are set by the liquidity provider. The keys to which equilibria emerge include 1) the liquidity provider sets prices by balancing his expected gain from trading with an uninformed investor against his expected loss from trading with an informed trader; 2) the informed trader, if he arrives, compares his information advantage to his information impact; and 3) the uninformed investor, if she arrives, compares her desire for satisfaction to her desire for fair value given offered prices.

\footnotetext{
${ }^{15}$ Proofs of results not stated as propositions are available upon request.
} 
The liquidity provider maximizes his expected profit from each trade subject to a zero expected profit constraint for each quantity. Equilibrium prices reflect the probabilistic presence of an uninformed investor and an informed trader: ${ }^{16}$

$$
P^{i j}=\frac{(1-\alpha) \pi^{i j} E+\alpha\left[\delta \phi^{i j \mid P L} P_{L}+(1-\delta) \phi^{i j \mid P H} P_{H}\right]}{(1-\alpha) \pi^{i j}+\alpha\left[\delta \phi^{i j \mid P L}+(1-\delta) \phi^{i j \mid P H}\right]} .
$$

Recall that $E$ is equal to the unconditional expected value of $P^{*}$.

In equilibrium, the informed trader never trades on the bid side when $P^{*}$ is greater than the uninformed expected value, nor on the ask side when $P^{*}$ is less than the uninformed expected value. This requires that $\phi^{A j \mid P L}=\phi^{B j \mid P H}=0$ in Equation (4), which then simplifies to

$$
\begin{aligned}
& P^{A j}=\frac{(1-\alpha) \pi^{A j} E+\alpha(1-\delta) \phi^{A j \mid P H} P_{H}}{(1-\alpha) \pi^{A j}+\alpha(1-\delta) \phi^{A j \mid P H}}, \\
& P^{B j}=\frac{(1-\alpha) \pi^{B j} E+\alpha \delta \phi^{B j \mid P L} P_{L}}{(1-\alpha) \pi^{B j}+\alpha \delta \phi^{B j \mid P L}} .
\end{aligned}
$$

As in Copeland and Galai (1983), the liquidity provider optimally offsets his expected losses from trading with the informed trader and his expected gains from trading with the uninformed investor. If there is no possibility of an informed trader's arrival $(\alpha=0)$, prices are set equal to the asset's uninformed expected value. When either an informed trader or an uninformed investor can arrive $(0<\alpha<1)$, the possibility of an informed trader pushes ask prices above the uninformed expected value and bid prices below it. The ask prices are weighted averages of the uninformed expected value and $P_{H}$, and the bid prices are weighted averages of the uninformed expected value and $P_{L}$. Finally, if there is no possibility of an uninformed investor's arrival $(\alpha=1)$, then both ask prices are set equal to $P_{H}$ and both bid prices are set equal to $P_{L}$.

If the informed trader trades when $P^{*}=P_{H}$, he only chooses a strategy that leads to a net long position. Similarly, when $P^{*}=P_{L}$, he only chooses a net short position.

In equilibrium, the uninformed investor does not trade if nature does not provide any motivation for trade, $Q^{*}=0$, or if she does not care at all about satisfaction, $\theta=0$. Further, the uninformed investor never trades on the bid side when her $Q^{*}$ is on the ask side nor on the ask side when her $Q^{*}$ is on the bid side.

We next characterize how each liquidity demander affects the other's choice in equilibrium. The uninformed investor is less likely to trade when prices are set to reflect a positive probability of an informed trade. In any equilibrium where the uninformed investor chooses not to trade a particular quantity, its price is set to eliminate any motive for the informed trader to trade. With the uninformed investor indifferent between trading the small and large quantities, the informed trader never chooses to trade the small quantity exclusively, but he might be encouraged by his information advantage to trade the large quantity exclusively. Finally, in any equilibrium where prices are set to reflect a positive probability that the uninformed investor trades, the informed trader never chooses to completely avoid trading if his information opportunity is on the same side of the market as the uninformed investor's $Q^{*}$.

\footnotetext{
${ }^{16}$ The price the liquidity provider quotes for any quantity that is not traded in equilibrium in our model is determined by the marginal liquidity demander's optimization. At this price, neither the informed trader nor the uninformed investor finds it beneficial to trade that quantity.
} 


\section{B. Analysis of Equilibria}

The mere possibility of multiple quantities in each period does not guarantee that all are traded in equilibrium. Earlier models such as Glosten and Milgrom (1985) and Bhattacharya and Spiegel (1991) examine the collapse of trade in the presence of severe informational asymmetries. In addition to this pure adverse-selection market breakdown, we find novel ways that an absence of trade may emerge even in markets with minimal informed trading.

An ostensibly multiple-quantity market can witness a lack of trading in some quantities not only as a consequence of adverse selection but also as a consequence of the uninformed investor's preferences. For example, the uninformed investor may choose to trade only the small quantity when the intensity of her desire for satisfaction is sufficiently low even though her $Q^{*}$ is large. Since equilibrium prices are set so that the informed trader also would trade only the small quantity, the large quantity is not traded regardless of who actually arrives. Analogously, the uninformed investor may choose to trade only the large quantity when the intensity of her desire for satisfaction is sufficiently high and her $Q^{*}$ is large, in which case equilibrium prices are set to preclude the trading of the small quantity. The desire for satisfaction may therefore explain some observed patterns in quantities traded.

In the extreme, a complete absence of trade can emerge in equilibrium. Again, this need not be driven exclusively by adverse selection but could instead be a natural consequence of the uninformed investor's preferences. As summarized in Proposition 2, trade may break down when the uninformed investor has a low exogenous demand for quantity and/or when her desire for satisfaction is low.

Proposition 2: An equilibrium without any trade can emerge not only when adverse selection dominates but also when

1) the uninformed investor's exogenous demand for quantity, $Q^{*}$, is zero or low, or

2) the uninformed investor's desire for satisfaction, $\theta$, is zero or low.

As next shown in Proposition 3, the uninformed investor must choose a mixing strategy for a multiple-quantity equilibrium to emerge. ${ }^{17}$ Were the uninformed investor not indifferent, she would choose to trade only one quantity and thus only one quantity would be traded in equilibrium. There are two possible multiple-quantity equilibria. In one, both types of liquidity demanders are indifferent between trading each quantity; in the other, the informed trader chooses to trade only the large quantity while the uninformed investor is indifferent between trading both quantities. Under particular parameter values for which the uninformed investor is indifferent between trading the two quantities, these equilibria are identical to those derived in Easley and O'Hara (1987), where multiple uninformed investors are each forced to trade a specific quantity. The equilibrium in which the informed trader trades only the large quantity is more likely to emerge for high $Q^{i L} / Q^{i S}$ ratios, as the informed trader's information advantage outweighs his information impact for large versus small trades. ${ }^{18}$

Proposition 3: An equilibrium in which all quantities are traded emerges when a specific intensity of desire for satisfaction motivates a mixing strategy for the uninformed investor.

\footnotetext{
${ }^{17}$ In the next section, we demonstrate that in the presence of heterogeneous uninformed investors who rationally maximize, multiple-quantity equilibria emerge for a broader range of parameters.

${ }^{18}$ While with only two quantities this effect could be due to either increment (the distance between neighboring quantities) or span (the total distance across all quantities), adding a third quantity demonstrates that this effect is due to increment rather than to span.
} 


\section{Equilibria with Heterogeneous Uninformed Investors}

Proposition 3 shows that with a single uninformed investor, a multiple-quantity equilibrium emerges only under a very specific parameterization. In this section, we relax the assumption that there is only one uninformed investor who might arrive to isolate the effect of multiple investors desiring various quantities. These investors continue to have a common intensity of desire for satisfaction (a common theta) but observe different realizations of the exogenous demand for quantity (heterogeneous $Q^{*} \mathrm{~s}$ ). ${ }^{19}$ Recall that the liquidity provider and the informed trader maximize based on a probabilistic assessment of the uninformed investor's behavior. The existing analysis extends naturally to the case of multiple uninformed investors, as the former probabilistic assessment of the distribution of $Q^{*}$ for one investor can here be thought of as the population distribution of $Q^{*}$ s for heterogeneous investors. Proposition 4 shows that heterogeneous uninformed investors, each choosing to trade only one quantity if she arrives, generate multiple-quantity equilibria under a broader set of parameter values than in a model with one uninformed investor.

PROPOSITION 4: An equilibrium in which all quantities are traded can emerge when heterogeneous uninformed investors each choose to trade only one quantity.

We next show that the classic adverse selection intuitions may fail to hold with multiple uninformed investors. For example, while it remains typically true that bid-ask spreads increase in the likelihood of an informed trader, Proposition 5 shows that bid-ask spreads for some quantities may actually decrease in the likelihood of an informed trader when the uninformed investors' preferences are the more binding. ${ }^{20}$ Intuitively, when the informed fraction of the population increases overall, it need not increase for every quantity. If the uninformed investors optimally choose to trade differently in equilibrium as the probability of an informed arrival changes, then the fraction of informed traders at some particular quantity may actually decrease.

\section{PROPOSITION 5: Bid-ask spreads for some quantities may be decreasing in the fraction of liquidity demanders who are informed, $\alpha$.}

Another implication of the uninformed investors' choosing to trade optimally when prices are set to reflect a positive probability of informed trading concerns the value of private information specific to an asset. Proposition 6 shows that when uninformed investors have a high intensity of desire to trade that asset, they are likely to trade a quantity despite prices set to reflect the possibility of an informed trader. In contrast, when uninformed investors have a low intensity of desire to trade that asset, they are less likely to trade a quantity when prices are set to reflect the possibility of an informed trader, making the informed trader's private information less valuable to him. ${ }^{21}$

PROPOSITION 6: Private information specific to an asset is more valuable to an informed trader when uninformed investors have high intensity of desire to trade that asset than when they have no desire to trade that asset.

\footnotetext{
${ }^{19}$ For evidence of heterogeneous demand, see Bagwell (1992) and Hodrick (1999).

${ }^{20}$ Spiegel and Subrahmanyam (1992) find that prices need not be monotonic in the number of informed traders in a Kyle-type framework with rational uninformed investors.

${ }^{21}$ This is consistent with the result in models such as Kyle (1985), in which the informed trader's profits depend positively on the variance (intensity) of noise trading.
} 


\section{Empirical Implications}

The model yields several novel empirical implications.

Implication 1. By Proposition 1, investors need not trade off satisfaction for fair value. That is, although investors who trade less than their desired quantity have less satisfaction of demand at a worse price, their ability to attain fair value need not be compromised. We observe such behavior by index portfolio managers who trade illiquid securities in advance of index reconstitution dates, as detailed in Madhavan (2003). ${ }^{22}$ Those who bear such tracking error seek their desired quantity at a price closer to fair value. The critical trade-off between price and tracking error faced by these managers highlights the need for more comprehensive measures of execution quality, as the traditional, lower-dimensional measures such as bid-ask spreads are unable to fully capture the price-quantity trade-off.

Implication 2. By Proposition 2, the mere existence of multiple quantities does not ensure that all quantities are traded. In the extreme, an asset may completely cease to trade even absent significant informed presence when uninformed investors have little desire to trade. This observation may explain the general lack of secondary trading in the municipal bond market, where investor demand is often met at new issuance: from March 1998 to May 1999, 71\% of all municipal issues were not traded in the secondary market (Green, Hollifield, and Schurhoff, 2007).

Implication 3. By Proposition 3, assets that can trade only in large quantity increments give rise to informed trades concentrated in certain quantities. This implication offers a novel explanation for stock splits: since a split reduces the increment between traded quantities, it should diffuse the presence of informed traders. As a consequence, we predict that portfolio managers favor positions in stocks after they split. Testing this insight with measures of liquidity that have sufficiently high dimensionality might also help resolve the currently mixed evidence about the change in liquidity and firm value around stock splits. ${ }^{23}$

Implication 4. By Proposition 4 combined with Proposition 2, in a market with many heterogeneous uninformed investors, the number of quantities traded is increasing in their desire for satisfaction. At a low (or zero) desire for satisfaction, the uninformed investors choose not to trade; at a somewhat higher desire for satisfaction, they choose to trade, but not all quantities; at a very high (or infinite) desire for satisfaction, they choose to trade all quantities. This new explanation for trade-size clustering predicts the consequences of the 2003 Securities and Exchange Commission reform, which requires fund managers to disclose holdings quarterly instead of semiannually. It also explains the seasonality in trade-size clustering documented by Moulton (2005) in the foreign exchange market.

Implication 5. By Proposition 5, bid-ask spreads may be decreasing in the fraction of liquidity demanders who are informed when the uninformed investors' preferences are the more binding. ${ }^{24}$ Building on the argument of Edelen (1999) that hedge fund trading is relatively more information-based, Proposition 5 may explain why the recent influx of hedge funds into asset

\footnotetext{
${ }^{22}$ Greenwood (2005) quantifies the magnitude of the cost of strictly replicating the index when the Nikkei 225 Index was redefined in April, 2000. Though most constituents of the index were unchanged, he estimates that if institutions could have waited at least 10 weeks after the event before rebalancing, they could have avoided a loss of 3 billion yen.

${ }^{23}$ See, for example, Baker and Gallagher (1980), Fernando, Krishnamurthy, and Spindt (1999), Ikenberry and Ramnath (2002), and Lamoureux and Poon (1987).

${ }^{24}$ This insight might explain the paradoxical finding of Chakravarty and McConnell (1997) that bid-ask spreads were sometimes improved by Ivan Boesky's illegal informed trading.
} 
markets previously dominated by less-informed investors has not resulted in a widening of bidask spreads. In fact, the New York Mercantile Exchange documents that increased hedge fund participation has actually narrowed bid-ask spreads for natural gas and crude oil futures (New York Mercantile Exchange, 2005). ${ }^{25}$

Implication 6. By Proposition 6, private information specific to an asset may be more valuable when uninformed investors have an intense desire to trade than when they have little desire to trade. This suggests that private information about a stock widely held by index replicators is, all else equal, more valuable than private information about a nonindex stock. This observation provides a new interpretation of the index-inclusion results documented in the literature including Shleifer (1986) and Beneish and Whaley (1996) and may also predict cross-sectional variation in abnormal returns dependent on the extent of active versus passive index replication.

\section{Conclusion}

We define an asset to be perfectly liquid if a portfolio manager can trade the quantity she desires when she desires at a price not worse than the uninformed expected value. In practice, however, a portfolio manager is limited by both what she needs to attain and the ease with which she can attain it, making her sensitive to three dimensions of liquidity: price, timing, and quantity. Here we focus on the trade-off between sacrificing price and quantity instead of the canonical price-time trade-off to generate novel empirical implications.

We provide new insights into the trading patterns around events including index reconstitutions, new issuances, stock splits, and changes in portfolio disclosure requirements. Note that even completely predictable events can create important liquidity considerations for the portfolio manager. We also redress classic adverse selection intuitions, providing novel explanations for bid-ask spreads for some quantities that are decreasing in the fraction of informed traders and for cross-sectional variation in the abnormal returns documented around index inclusion.

The findings in this paper also provide a new perspective on optimal fund size. Through the fund size choice, portfolio managers to some extent endogenize their key liquidity constraints. Some small funds engage in mutual fund splits, which have no price effect but seem to encourage fund inflows, thereby reducing the manager's sensitivity to redemptions. At the other extreme, some large funds close to new investment to halt fund inflows, reducing the manager's imminent need to invest. ${ }^{26}$

This paper addresses the questions of what liquidity is and how it should be measured from a fundamental perspective, abstracting from the details of specific assets and market mechanisms. The general concept of liquidity and the ease with which one can execute a trade should apply equally well to any asset, from exchange-traded equities to over-the-counter bonds, real estate, and even baseball cards traded among children on the school bus. While this paper explores how liquidity specifically affects the mutual fund portfolio manager in her price-quantity trade-off, its general theoretical model and implications, as developed in Hodrick and Moulton (2005), extend far more broadly.

\footnotetext{
${ }^{25}$ Alternatively, the presence of hedge funds may facilitate effective search as developed in Duffie, Garleanu, and Pedersen (2005).

${ }^{26}$ Coval and Stafford (2007) confirm that net fund flows pressure portfolio managers to trade.
} 


\section{Appendix: Proofs of Propositions}

PROPOSITION 1: The desire for fair value can complement, substitute for, or be independent of the desire for satisfaction. Hence, an uninformed investor need not always trade off satisfaction for fair value.

Proof: We prove the result for the ask side of the market and a positive $Q^{*}$; the proof for the bid side of the market and negative $Q^{*}$ is analogous and is available on request.

Recall the uninformed investor's maximization for positive $Q^{*}$ :

$$
\max _{Q^{i j}} Q^{i j}\left(E-P^{i j}\right)-\theta\left(Q^{*}-Q^{i j}\right)
$$

The fair value term is always decreasing in $Q^{i j}$. Since all quantities on the ask side are nonnegative by construction, there are three possible cases.

Case (a): $Q^{*}>Q^{i j}$

$\Rightarrow$ the fair value term is decreasing in $Q^{i j}$ and the satisfaction term is increasing in $Q^{i j}$.

$\Rightarrow$ the fair value effect is complementary to satisfaction.

Case (b): $Q^{*}<Q^{i j}$

$\Rightarrow$ the fair value term and the satisfaction term are both decreasing in $Q^{i j}$.

$\Rightarrow$ the fair value effect is a substitute for satisfaction.

Case (c): $Q^{*}=Q^{i j}$

$\Rightarrow$ the fair value term is decreasing in $Q^{i j}$ and the satisfaction term is zero.

$\Rightarrow$ the fair value effect is independent of satisfaction. Q.E.D.

Proposition 2: An equilibrium without any trade can emerge not only when adverse selection dominates, but also when

1) the uninformed investor's exogenous demand for quantity, $Q^{*}$, is zero or low, or

2) the uninformed investor's desire for satisfaction, $\theta$, is zero or low.

Proof: Recall from Section II.A that the informed trader never chooses to trade a quantity that the uninformed investor would not trade. Therefore, an absence of trade emerges whenever the uninformed investor chooses not to trade.

1) This result emerges directly from Equation (3).

2) Using Equation (3), we characterize those specific parameter values on the ask side of the market when no trade is optimal for the uninformed investor.

For the uninformed investor to prefer no trade to trading the small quantity,

$$
-\theta Q^{*}>Q^{A S}\left(E-P^{A S}\right)-\theta\left(Q^{*}-Q^{A S}\right),
$$


$\Rightarrow-\theta Q^{A S}>Q^{A S}\left(E-P^{A S}\right)$,

$\Rightarrow \theta<\left(P^{A \mathrm{~S}}-E\right)$.

For the uninformed investor to prefer no trade to trading the large quantity,

$-\theta Q^{*}>Q^{A L}\left(E-P^{A L}\right)-\theta\left(Q^{*}-Q^{A L}\right)$

$\Rightarrow-\theta Q^{A L}>Q^{A L}\left(E-P^{A L}\right)$

$\Rightarrow \theta<\left(P^{A L}-E\right)$.

By inspection, these conditions hold for lower values of theta. Analogous conditions on theta emerge on the bid side. Q.E.D.

PROPOSITION 3: An equilibrium in which all quantities are traded emerges when a specific intensity of desire for satisfaction motivates a mixing strategy for the uninformed investor.

Proof: Recall from Section II.A that the informed trader never chooses to trade a quantity that the uninformed investor does not trade. Therefore, a multiple-quantity equilibrium emerges only if the uninformed investor chooses to trade both quantities, implying a mixing strategy. Using Equation (3), we find those specific parameter values on the ask side of the market.

$$
\begin{aligned}
& Q^{A S}\left(E-P^{A S}\right)-\theta\left(Q^{*}-Q^{A S}\right)=Q^{A L}\left(E-P^{A L}\right)-\theta\left(Q^{*}-Q^{A L}\right) \\
& \Rightarrow \theta=\frac{Q^{A L}\left(E-P^{A L}\right)-Q^{A S}\left(E-P^{A S}\right)}{\left(Q^{A S}-Q^{A L}\right)}
\end{aligned}
$$

An analogous condition on theta emerges on the bid side. Q.E.D.

PROPOSITION 4: An equilibrium in which all quantities are traded can emerge when heterogeneous uninformed investors each choose to trade only one quantity.

Proof: We offer the following example in which the multiple-quantity equilibrium emerges when heterogeneous uninformed investors each optimally trade their $Q^{*}$ and the informed trader trades only the large quantity.

Example:

$$
\begin{array}{ccccc}
P_{H}=110 & P_{L}=100 & \delta=0.5 & Q^{A L}=21 & Q^{A S}=10 \\
\psi^{A \mathrm{~L}}=0.5 & \psi^{A S}=0.5 & \theta=10 & \alpha=0.50
\end{array}
$$

Under these parameter values, the informed trader and an uninformed investor with $Q^{*}=21$ trades $Q^{A L}$ at 107.50, while an uninformed investor with $Q^{*}=10$ trades $Q^{A S}$ at 105.00. This Nash equilibrium is also the optimal amongst potential equilibria as determined by a social planner maximizing uninformed investors' weighted utility. Q.E.D.

PROPOSITION 5: Bid-ask spreads for some quantities may be decreasing in the fraction of liquidity demanders who are informed, $\alpha$.

Proof: We offer the following example in which the ask price for small quantity is decreasing in alpha, the fraction of liquidity demanders who are informed. Consider a parameterization under which the extant equilibrium has the large quantity traded by only the informed trader and those uninformed investors who receive the largest $Q^{*}$. As the fraction of liquidity demanders who are informed rises, all liquidity demanders (including those uninformed investors who receive the 
large $Q^{*}$ ) may optimally shift to trading the small quantity, and the bid-ask spread for the small quantity can actually decline.

Example:

$P_{H}=110 \quad P_{L}=100 \quad \delta=0.5 \quad Q^{A L}=10.5 \quad Q^{A S}=10$

$\psi^{A L}=0.8 \quad \psi^{A S}=0.2 \quad \theta=0.95$

When $\alpha=0.20$

Equilibrium: uninformed investors and informed trader trade only large quantity

Prices: $\quad P^{A S}=105.63 \quad P^{A L}=105.56$

Recall that since the liquidity provider must also have zero expected profit for the small quantity, he sets its price such that, were the informed trader and the uninformed investor who received a small $Q^{*}$ to instead trade the small quantity, the liquidity provider would expect to break even.

When $\alpha=0.21$

Equilibrium: uninformed investors and informed trader trade only small quantity

Prices: $\quad P^{A S}=105.59 \quad P^{A L}=105.80$

This Nash equilibrium is also the optimal among potential equilibria as determined by a social planner maximizing uninformed investors' weighted utility. Q.E.D.

Proposition 6: Private information specific to an asset is more valuable to an informed trader when uninformed investors have high intensity of desire to trade that asset than when they have no desire to trade that asset.

Proof: We first show that there is no value to private information specific to an asset when uninformed investors have no desire to trade that asset. Section II.A states that, in equilibrium, the uninformed investor does not trade if she does not care at all about satisfaction, and that the informed trader never chooses to trade in the absence of the uninformed investor. Since prices would be set equal to $P_{H}$ on the ask side and $P_{L}$ on the bid side to eliminate any motive for the informed trader to trade, there is no value to private information specific to an asset in this case.

We next show that private information specific to an asset is valuable when uninformed investors have a high intensity of desire to trade that asset. Consider the extreme case where the intensity of desire to trade is infinite, such that the uninformed investors must trade their desired quantity. Equations (4.1) and (4.2) show that when uninformed investor trade a specific quantity, its equilibrium price is less than $P_{H}$ on the ask side and greater than $P_{L}$ on the bid side. This allows the informed trader to profit from his private information. Q.E.D.

\section{References}

Admati, A.R. and P. Pfleiderer, 1988, “A Theory of Intraday Patterns: Volume and Price Variability,” Review of Financial Studies 1, 3-40.

Ait-Sahalia, Y. and M.W. Brandt, 2001, "Variable Selection for Portfolio Choice," Journal of Finance 56, 1297-1351. 
Bagehot, W. pseudonym J. Treynor, 1971, “The Only Game in Town,” Financial Analysts Journal 27, 12-14, 22.

Bagwell, L.S., 1992, "Dutch Auction Repurchases: An Analysis of Shareholder Heterogeneity," Journal of Finance 47, 71-105.

Baker, H.K. and P.L. Gallagher, 1980, “Management's View of Stock Splits,” Financial Management 9 , 73-77.

Beneish, M.D. and R.E. Whaley, 1996, "An Anatomy of the 'S\&P Game': The Effects of Changing the Rules," Journal of Finance 51, 1909-1930.

Berk, J.B. and R.C. Green, 2004, "Mutual Fund Flows and Performance in Rational Markets," Journal of Political Economy 112, 1269-1295.

Bhattacharya, U. and M. Spiegel, 1991, “Insiders, Outsiders and Market Breakdowns,” Review of Financial Studies 4, 255-282.

Black, F., 1971, “Towards a Fully Automated Exchange, Part I,” Financial Analysts Journal 27, 29-35, 44.

Bloomfield, R.J., M. O’Hara, and G. Saar, 2005, “The 'Make or Take' Decision in an Electronic Market: Evidence on the Evolution of Liquidity," Journal of Financial Economics 75, 165-199.

Bollen, N.P.B. and J.A. Busse, 2001, “On the Timing Ability of Mutual Fund Managers,” Journal of Finance 56, 1075-1094.

Bollen, N.P.B. and J.A. Busse, 2004, "Short-Term Persistence in Mutual Fund Performance," Review of Financial Studies 18, 569-597.

Brown, K.C., W.V. Harlow, and L.T. Starks, 1996, “Of Tournaments and Temptations: An Analysis of Managerial Incentives in the Mutual Fund Industry," Journal of Finance 51, 85-110.

Campbell, J.Y., S.J. Grossman, and J. Wang, 1993, "Trading Volume and Serial Correlation in Stock Returns," Quarterly Journal of Economics, 905-939.

Chakravarty, S. and J.J. McConnell, 1997, “An Analysis of Prices, Bid/Ask Spreads, and Bid and Ask Depths Surrounding Ivan Boesky's Illegal Trading in Carnation's Stock," Financial Management 26, 18-34.

Copeland, T. and D. Galai, 1983, "Informational Effects on the Bid Ask Spread," Journal of Finance 38, 1457-1469.

Coval, J. and E. Stafford, 2007, “Asset Fire Sales (and Purchases) in Equity Markets,” Journal of Financial Economics 86, 497-512.

Duffie, D., N. Garleanu, and L. Heje Pedersen, 2005, “Over-the-Counter Markets,” Econometrica 73, 1815-1847.

Easley, D. and M. O'Hara, 1987, "Price, Trade Size and Information in Securities Markets," Journal of Financial Economics 19, 69-90.

Edelen, R.M., 1999, "Investor Flows and the Assessed Performance of Open-End Mutual Funds," Journal of Financial Economics 53, 439-466.

Fernando, C.S., S. Krishnamurthy, and P.A. Spindt, 1999, "Is Share Price Related to Marketability? Evidence from Mutual Fund Share Splits,” Financial Management 28, 15-31.

Foster, F. D. and S. Viswanathan, 1990, “A Theory of Interday Variations in Volume, Variance, and Trading Costs in Securities Markets," Review of Financial Studies 3, 593-624.

Glosten, L.R. and P. Milgrom, 1985, "Bid, Ask and Transaction Prices in a Specialist Market with Heterogeneously Informed Traders,” Journal of Financial Economics 14, 71-100. 
Goldstein, M. and K. Kavajecz, 2000, "Eighths, Sixteenths and Market Depth: Changes in Tick Size and Liquidity Provision on the NYSE," Journal of Financial Economics 56, 125-149.

Green, R.C., B. Hollifield, and N. Schurhoff, 2007, "Financial Intermediation and the Costs of Trading in an Opaque Market," Review of Financial Studies 20, 275-314.

Greenwood, R., 2005, "Short- and Long-Term Demand Curves for Stocks: Theory and Evidence on the Dynamics of Arbitrage," Journal of Financial Economics 75, 607-649.

Hodrick, L.S, 1999, “Does Stock Price Elasticity Affect Corporate Financial Decisions?” Journal of Financial Economics 52, 225-256.

Hodrick, L.S. and P.C. Moulton, 2005, "Liquidity,” Columbia Business School Working Paper.

Investment Company Institute, 2008, Investment Company Fact Book, Washington, DC, Investment Company Institute.

Ikenberry, D. and S. Ramnath, 2002, "Underreaction to Self-Selected News Events: The Case of Stock Splits," Review of Financial Studies 15, 489-526.

Journal of Indexes, 2005, Available at: http://www.journalofindexes.com (accessed July 26, 2005).

Kyle, A.S., 1985, “Continuous Auctions and Insider Trading," Econometrica 53, 1315-1335.

Lamoureux, C. and P. Poon, 1987, “The Market Reaction to Stock Splits," Journal of Finance 42, 1347-1370.

Lo, A.W., H. Mamaysky, and J. Wang, 2004, “Asset Prices and Trading Volume Under Fixed Transactions Costs,” Journal of Political Economy 112, 1054-1090.

Longstaff, F., 2005, "Asset Pricing in Markets with Illiquid Assets," UCLA Anderson School Working Paper.

Madhavan, A., 2003, “The Russell Reconstitution Effect," Financial Analysts Journal 59, 51-64.

Moulton, P.C., 2005, "You Can’t Always Get What You Want: Trade-Size Clustering and Quantity Choice in Liquidity," Journal of Financial Economics 78, 89-119.

New York Mercantile Exchange, 2005, Available at: http://www.massoilheat.org/ (accessed March 1, 2005).

O'Hara, M., 1995, Market Microstructure Theory, Cambridge, MA, Blackwell.

O’Neal, E. S., 2004, "Purchase and Redemption Patterns of US Equity Mutual Funds," Financial Management 33, 63-90.

Shleifer, A., 1986, “Do Demand Curves for Stocks Slope Down?” Journal of Finance 41, 579-590.

Spiegel, M. and A. Subrahmanyam, 1992, "Informed Speculation and Hedging in a Noncompetitive Securities Market," Review of Financial Studies 5, 307-329.

Vayanos, D., 2004, "Flight to Quality, Flight to Liquidity, and the Pricing of Risk," London School of Economics Working Paper.

Warther, V.A., 1995, “Aggregate Mutual Fund Flows and Security Returns," Journal of Financial Economics $39,209-235$. 